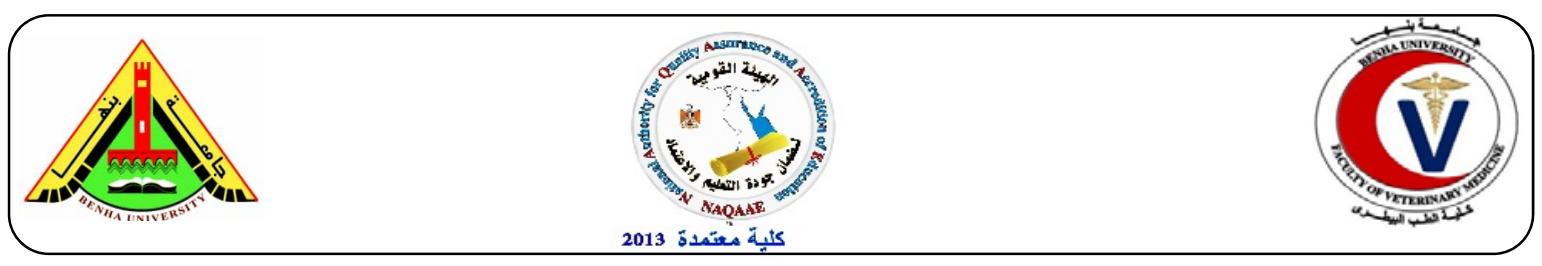

\title{
Comparison of modified decontamination methods with culture systems for primary isolation of Mycobacterium bovis from bovine tissues
}

\author{
Nasr E.A. ${ }^{1}$, Marwah M. ${ }^{1}$, Abdel Rahman M. ${ }^{1}$ and Shafeek H. ${ }^{2}$ \\ ${ }^{I}$ Department of Bacterial Diagnostic Products (Tuberculosis), Veterinary Serum and Vaccine \\ Research Institute, Abassia, Cairo, Egypt. ${ }^{2}$ General Organization of Veterinary Service, Giza.
}

\begin{abstract}
A B S T R A C T
A definitive diagnosis of $M$. bovis infection in animals depends on the isolation of the organism, as the optimum condition for the primary isolation of $M$. bovis infection has not been determined. In this study a total number of 2550 cattle from different governorates in Egypt were tested by Single Intradermal Cervical (SID) tuberculin skin test. Positive reacted cattle $(\mathrm{no}=42,1.6 \%)$ were slaughtered and suspected lesions were collected, these samples were decontaminated by using three different methods, which were $0.75 \%$ Hexadecyl Pyridinium Chloride (HPC), 5\% oxalic acid and $6 \%$ sulphuric acid. Isolation of mycobacteria from 42 samples by using these decontaminated methods were of 34 (80.9 $\%), 30(71.4 \%)$ and 28 (66.6 \%), respectively. So it could be concluded that using HPC method as decontaminated agent revealed high rate of isolation of mycobacteria with less contamination $(7.1 \%)$ than the other two methods.
\end{abstract}

Keywords: Mycobacterium bovis - HPC- decontamination - oxalic acid - sulphuric acid.

(http://www.bvmj.bu.edu.eg) $\quad$ (BVMJ-30(1): 59-67, 2016)

\section{INTRODUCTION}

$M$ ycobacterium bovis causes bovine tuberculosis, an important disease of cattle in several countries. It remains an important public health concern because of its zoonotic potential and re- emergence in animals and humans (OIE, 2009 and Thoen et al., 2009). Tuberculin tests are performed and animals that are positive reactors are slaughtered (Wayne and Kubica, 1986). Nevertheless, the definitive diagnosis can only be achieved by isolation of $M$. bovis from clinical specimens, average of pretreatment and processing procedures (homogenization, decontamination and concentration) were used and also the culture media that inhibit contaminating organism, are employed to facilitate recovery of mycobacteria (Murray et al., 2007). Decontamination with acids, alkalies or even detergents is a common practice as mycobacteria are resistant to such agents (Burdz et al., 2003). Certain decontaminating agents destroy a substantial number of mycobacteria along with the contaminants, while others are too weak to destroy them (Streingart et al., 2006 and de Kantor Lazlo, 1998). The resulting consequence is a costly delay in detecting the tubercle bacilli (Tomita et al., 2008). Quaternary ammonium compounds, sodium hydroxide, sulphuric acid, oxalic acid and Hexadecyl Pyridinium Chloride (HPC) have been used for decontamination of clinical specimens (OIE, 2009). The method traditionally used to isolate $M$. bovis from bovine tissues is the Petroff method, that uses $4 \% \mathrm{NaOH}$ which is effective in removing the contaminants, but a large number of mycobacteria are also killed (de Kantor Lazlo, 1998). Using of 2\% of $\mathrm{NaOH}$ is less practiced due to its inability 
to destroy all the unwanted microbes (Laidlaw 1989 and Tomita et al., 2008).

HPC $0.75 \%$ and Sulfuric acid $6 \%$ are presented of low toxicity for M. bovis, AN5 strain. The Sulfuric Acid is the method used in the Brazilian reference laboratory for animal diseases (LANAGRO). HPC does not require the neutralizing stage, presenting a faster processing time (Holanda et al., 2002). In 1930, Coper and Uyei described the use oxalic acid as a decontaminant for recovery of $M$. tuberculosis from respiratory specimen. Later, oxalic acid treatment was recommended for use in recovering acid fast bacilli from heavily contaminated specimens (Yajko et al., 1993). The suitable decontamination process is an absolute necessity that may provide sufficient control in removing the undesirable contaminants for the best result.

The present study was objected to compare three different decontamination methods for isolation of Mycobacteria from suspected lesions from different localities governorates in Egypt.

\section{MATERIAL AND METHODS}

\subsection{Tuberculin skin test:}

A total of number of 2550 cattle from El Monufia, El Sharkia, El Gharbia and Ismalia were tested by Single Intradermal Cervical (SID) tuberculin skin test as performed by OIE 2009. All tuberculin positive reactor animals were slaughtered and subjected it to post mortem examination.

\subsection{Post-mortem examination:}

It was done on positive reactor animals, examination of different lymph nodes and organs were applied. The retro pharyngeal, sub maxillary, parotid, bronchial, mediastinal, hepatic and pre scapular lymph nodes these nodes were sliced serially in situ. The mesenteric lymph nodes were examined visually and by palpation, and a portion of the chain was also sliced serially. The lungs, spleen and liver were examined visually and by palpation. All macroscopic lesions and any congestion detectedin these previous tissues during examination at the abattoir were removed for laboratory examination.

\subsection{Samples processing using different decontamination methods (Palmino and Portaelo 1998 and Medeiros et al., 2011).}

A composite sample, consisting of about 15 $\mathrm{g}$ of tissue from each carcass, was sliced into small pieces using sterile scissors and macerated with sterile sand. The macerated tissue was resuspended in $40 \mathrm{ml}$ of sterile water centrifuged, $15 \mathrm{ml}$ of the supernatant was divided into three aliquots of $5 \mathrm{ml}$ for decontamination as in the following diagram. Smears were prepared from the sediments of each samples before and after decontamination and stained by Ziehl Nielsen for visualization of acid fast bacilli. Each pellet was resuspended in $2 \mathrm{ml}$ of sterile distilled water, and $0.2 \mathrm{ml}$ of the solution was inoculated onto two slops of Lowenstein - Jensen medium (with $0.5 \%$ pyruvate). The remaining suspension was used to prepare smears and stored for further studies. Cultures were incubated at $37^{\circ} \mathrm{C}$ and observed weekly for 12 weeks. The contaminated cultures were removed and recorded.

\subsection{Bacteriological examination and Identification of isolated acid fast bacilli:}

Identification of isolates as acid fast mycobacterial growth was done by standard biochemical tests (Niacin production, Nitrate reduction, Catalase activity at $68{ }^{\circ} \mathrm{C}$ and at room temperature, Tween 80 hydrolysis, Aryl sulphatase and Thiophen 2 Carboxylic acid Hydrazide (TCH) sensitivity, etc.) as per CDC Manual (OIE, 2009). 


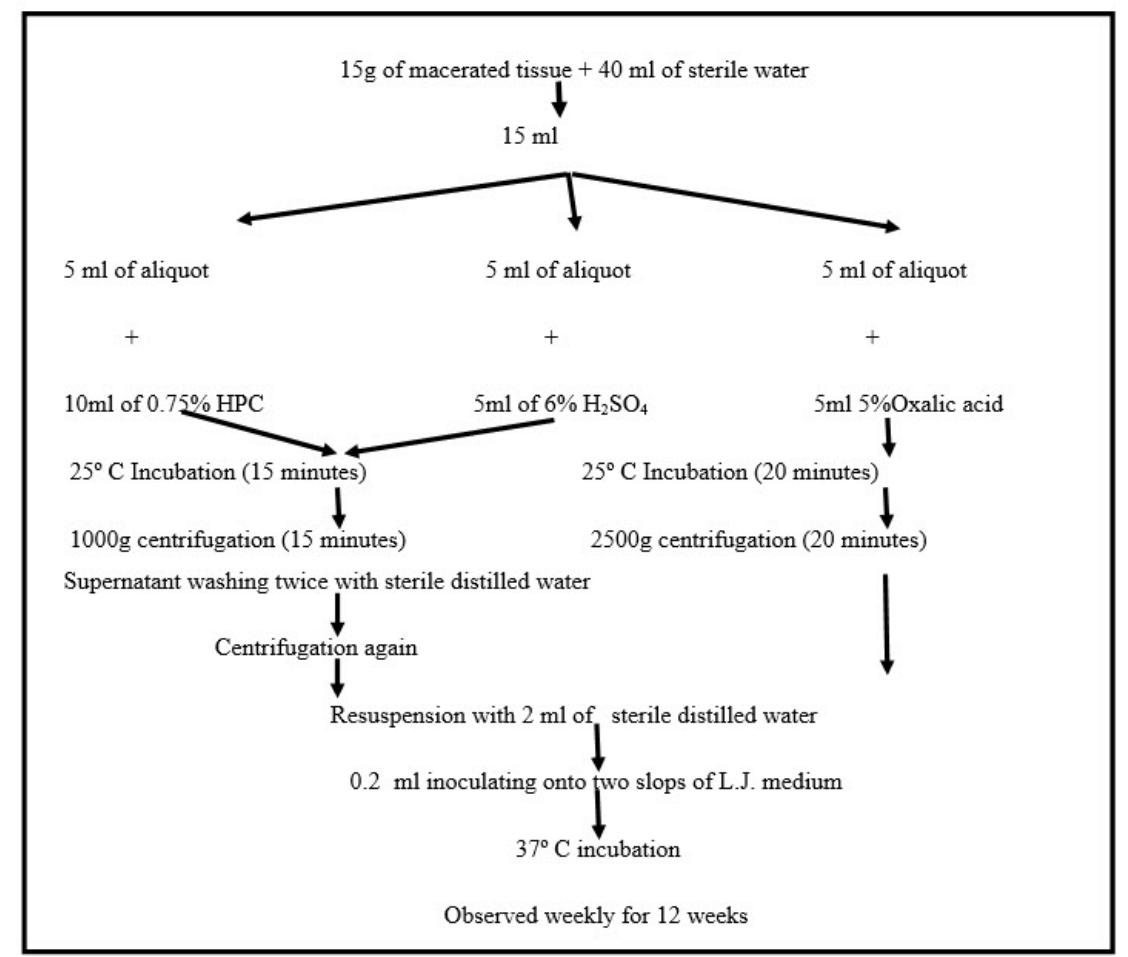

\section{RESULTS}

\subsection{Results of tuberculin skin test in cattle:}

The obtained results demonstrated the prevalence of tuberculin positive reactor animals, where out of 2550 tuberculin tested cattle, were $42(1.6 \%)$ (Table- 1$)$.

\subsection{Results of post mortem finding from tuberculin positive slaughtered cattle:}

Out of 42 tuberculin reactor animals, $33(78.6 \%)$ showed visible and $9(21.4 \%)$ had no visible lesions, on the same time the visible lesions showing $4(9.5 \%)$ head, $13(30.9 \%)$ respiratory, $3(7.1 \%)$ digestive, $9(21.4 \%)$ mixed and $4(9.5 \%)$ generalized as shown in the same table (Table-2).

\subsection{The recovery rates of Mycobacteria by using different decontamination methods:}

The obtained results in table (3) and figure (1) indicated the number and rates of mycobacterium isolated by using the different methods of decontamination. These results indicate that $0.75 \%$ HPC as a decontamination method revealed high rate of isolation than the other two methods ( $5 \%$ oxalic acid and $6 \%$ sulphuric acid).

\subsection{Contamination rates obtained in the different decontamination methods:}

It is clear from table (4) and figure (1) that the lower contamination rate was found in using $\mathrm{HPC}(7.1 \%)$ followed by $\mathrm{H}_{2} \mathrm{SO}_{4}$ $(9.5 \%)$ and Oxalic (11.9\%).

\subsection{Identification of mycobacterial isolates:}

Bacteriological identification as shown in table (5) revealed that $27(81.8 \%)$ out of 33 cattle showing visible lesions were identified as $M$. bovis, 2 out of 9 cattle $(22.2 \%)$ without visible lesions were unidentified slow grower mycobacteria and 1 out of $33(3.0 \%)$ with visible lesions were unidentified slow grower mycobacteria. 
Table (1) Results of Tuberculin skin test in cattle.

\begin{tabular}{cccc}
\hline Governorates & No. of tested cattle & \multicolumn{2}{c}{ Positive tuberculin reactors } \\
\hline & & No. & $\%$ \\
El Monufia & 750 & 13 & 1.7 \\
El Sharkia & 550 & 8 & 1.6 \\
El Gharbia & 525 & 7 & 1.3 \\
Ismalia & 725 & 14 & 1.9 \\
Total & 2550 & 42 & 1.6 \\
\hline
\end{tabular}

Table (2) Percentage of tuberculous lesions in slaughtered positive reactors cattle.

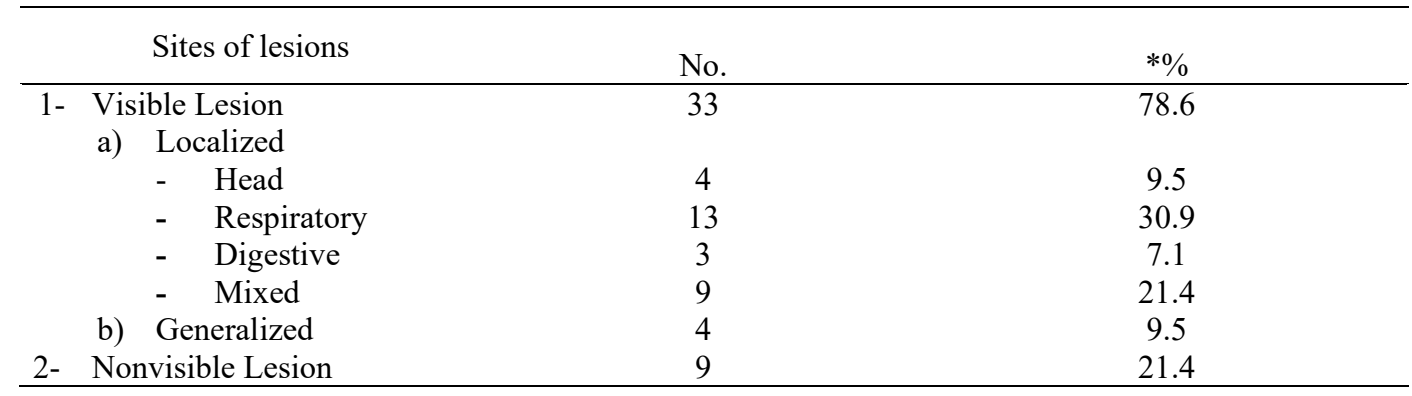

$\% *$ : Calculated according to the total number of tuberculin positive cows (42).

Table (3): The recovery rates of Mycobacteria by using different decontamination methods.

\begin{tabular}{|c|c|c|c|c|c|c|c|}
\hline \multirow{2}{*}{ Sites of lesions (No.) } & \multirow{2}{*}{ No. } & \multicolumn{2}{|c|}{ HPC } & \multicolumn{2}{|c|}{ Oxalic acid } & \multicolumn{2}{|c|}{ Sulphuric acid } \\
\hline & & No. & $* \%$ & No. & $* \%$ & No. & $* \%$ \\
\hline 1-Visible Lesion & 33 & $28 / 33$ & 84.8 & $25 / 33$ & 75.8 & $24 / 33$ & 72.7 \\
\hline A) Localized Head & 4 & $3 / 33$ & 9.1 & $2 / 33$ & 6.1 & $2 / 33$ & 6.1 \\
\hline $\begin{array}{l}\text { Respiratory (pulmonary } \\
\text { L.N + lung tissue) }\end{array}$ & 13 & $11 / 33$ & 33.3 & $9 / 33$ & 27.3 & $8 / 33$ & 24.2 \\
\hline $\begin{array}{l}\text { Digestive (liver + } \\
\text { mesenteric L.N) }\end{array}$ & 3 & $3 / 33$ & 9.1 & $3 / 33$ & 9.1 & $3 / 33$ & 9.1 \\
\hline $\begin{array}{l}\text { Mixed (liver + lung tissue } \\
+ \text { L.N) }\end{array}$ & 9 & $7 / 33$ & 21.1 & $7 / 33$ & 21.1 & $7 / 33$ & 21.1 \\
\hline B) Generalized & 4 & $4 / 33$ & 12.1 & $4 / 33$ & 12.1 & $4 / 33$ & 12.1 \\
\hline 2-Non visible Lesion & 9 & $6 / 9$ & 66.6 & $5 / 9$ & 55.6 & $4 / 9$ & 44.4 \\
\hline Total & 42 & $34 / 42$ & 80.9 & $30 / 42$ & 71.4 & $28 / 42$ & 66.6 \\
\hline
\end{tabular}

No.: Number. HPC: Hexadecyl Pyridinium Chloride. L.N: Lymph Node.

Table (4): Contamination rates obtained in the different decontamination methods.

\begin{tabular}{ccc}
\hline Decontamination methods & $\begin{array}{c}\text { Contamination detected in } \\
\text { processing samples (42) }\end{array}$ & \% of contamination \\
\hline HPC & 3 & 7.1 \\
Oxalic acid & 5 & 11.9 \\
$\mathrm{H}_{2} \mathrm{SO}_{4}$ & 4 & 9.5 \\
\hline
\end{tabular}

HPC: Hexadecyl Pyridinium Chloride 


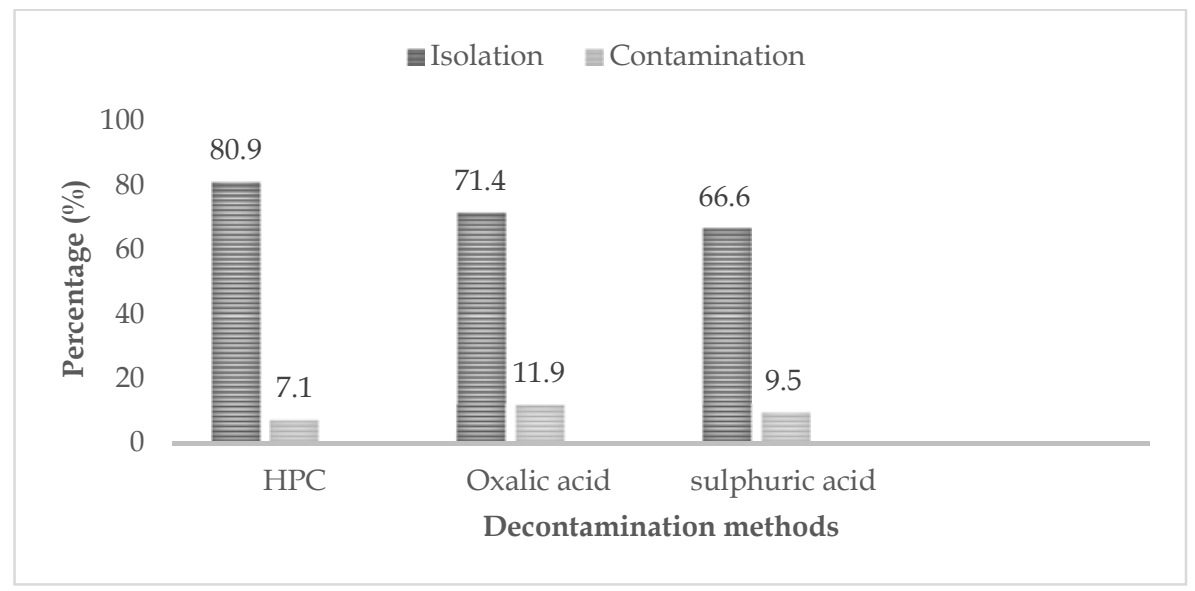

Figure (1): The relation between isolation of mycobacteria and contamination in the three decontamination methods.

Table (5): Identification of mycobacterial isolates.

\begin{tabular}{lccccc}
\hline \multirow{2}{*}{ Sites of lesions } & \multicolumn{3}{c}{ M. bovis } & \multicolumn{2}{c}{ Unidentified slow grower } \\
& No. & No. & $\%$ & No. & $\%$ \\
\hline 1-Visible Lesion & 33 & $27 / 33$ & 81.8 & $1 / 33$ & 3.0 \\
A) Localized Head & 4 & $3 / 33$ & 9.1 & - & - \\
$\quad$ Respiratory (pulmonary L.N + lung & 13 & $11 / 33$ & 33.3 & - & - \\
$\quad$ tissue) & 3 & $2 / 33$ & 6.1 & $1 / 33$ & 3.0 \\
$\quad$ Digestive (liver + mesenteric L.N) & 9 & $7 / 33$ & 21.2 & - & - \\
$\quad$ Mixed (liver + lung tissue + L.N) & 4 & $4 / 33$ & 12.1 & - & - \\
B) Generalized & 9 & $4 / 9$ & 44.4 & $2 / 9$ & 22.2 \\
2- Non visible Lesion & 42 & $31 / 42$ & 73.8 & $3 / 42$ & 7.1 \\
$\quad$ Total &
\end{tabular}

MOTT $=$ Mycobacterium Other Than Tuberculosis. No.: Number. L.N: Lymph Node.

\section{DISCUSSION}

Bovine tuberculosis, caused by $M$. bovis, is an infectious, chronic disease of domestic and wild animals, and causes zoonotic tuberculosis in humans (Corner et al., 2011). The tuberculin skin tests (TST) are currently the best available techniques for international field diagnosis of bovine tuberculosis (de la Rua- Domenech et al., 2006). In addition, adefinitive diagnosis can only achieved by isolation of the $M$. bovis from clinical or postmortem specimens (Corner et al., 2011). Attempts to recovery the pathogen in pure culture have frequently failed since the specimens were often highly contaminated and also due to use of insufficient or over- active decontamination procedures. Thus, the suitable decontamination process is an absolute necessity that may provide sufficient control in removing undesirable contaminants (Chatterjee et al., 2013). The objective of this study is to compare three different decontamination methods for isolation of Mycobacteria from suspected lesions. The results showed in table (1) demonstrated the prevalence of tuberculin positive reactor animals, where out of 2550 tuberculin tested cattle, were 42 (1.6\%). This ratio is comparatively lower than that given by other investigators in Egypt \{(Lotfy et al., 1960, 6.9\%) and (El battawy $2008,4.6 \%), 2.2\}$ and in other countries of 
Africa (Ameni and Erkihun, 2007 in Ethiopia $11.6 \%$; Borna et al., 2009, 8\% in Chad) and this may be due to that these farms performed the tuberculin test regularly and applied test and slaughter strategy (Gonzales et al., 1999). On theother hand, the prevalence recorded in the present study is comparatively higher than that given by other investigators (Shirma et al., 2003) and (Cleaveland et al., 2007) in Tanzania, as it was $1.3 \%$ and $0.9 \%$, respectively. Table (2) illustrated number and percentage of lesions in examined samples (42). These obtained results are more or less similar to the results recorded by Nasr (1997), who reported that, out of 66 reactor cattle, 60 cattle were slaughtered, 44 $(73.4 \%)$ had visible lesions [ $15(25 \%), 7$ (11.6\%), 15 (25\%), 7(11.6\%) pulmonary - extra pulmonary - mixed and generalized tuberculosis, respectively] and $16(26.6 \%)$ with non-visible lesions. While, Naglaa (2008) found that out of 115 tuberculin reactor animals, $85(73.91 \%)$ showed visible lesions $\{25(21.74 \%)$ respiratory, 10 $(8.69 \%)$ digestive, $30(26.09 \%)$ mixed and $20(17.39 \%)$ generalized $\}$ and $30(26.09 \%)$ had no visible lesions. Finally, Marwa (2011) reported that, out of 29 tuberculin reactor animals, $22(75.9 \%)$ showed visible lesions (VL) and 7 (24.1\%) had no visible lesions (NVL), on the same time the visible lesions showing [9 (31.0) \% respiratory, 4 $(13.8 \%)$ digestive, $6(20.7 \%)$ mixed and 3 $(10.3 \%)$ generalized]. The presence of tuberculin positive with no visible lesions was considered nonspecific reactions which may be attributed to sensitization by atypical mycobacteria or even closely related microorganisms especially members of the genus Nocardia or a combination of liver fluke with saprophytic mycobacteria (Waddington, 1965). From results obtained in table (3) and Figure (1) indicated the number and rates of mycobacterium isolated by using the different methods of decontamination. These results indicated that using of $0.75 \%$ HPC as decontaminated method revealed high rate of isolation than the other two methods ( $5 \%$ oxalic acid and
$6 \%$ sulphuric acid). The obtained results were in agreement with that reported by Corner et al. (1995), who evaluated four decontamination methods $(0.75 \%$ HPC, $5 \%$ oxalic acid, Benzalconium Chloride (BC)and $2 \% \mathrm{NaOH}$ ) for isolation of $M$. bovis from bovine tissue artificially contaminated with AN5 strain. They found that the use of HPC in concentration 1.5\% demonstrated better results than that obtained by using the concentration of 0.75\%. Moreover, Ambrosio et al. (2008) compared decontamination methods for bovine tissue samples; the HPC method had the best results, with a significant advantage compared to no treatment or treatment with sodium hydroxide or sulphuric acid. Finally, Medeiros et al. (2011) showed that the HPC was more effective than either petroff or sulphuric acid methods.

Genetic composition of mycobacteria could affect the success of decontamination, because antibiotic resistant strains have been described as more susceptible to alkaline agents (Yesilkaya et al., 2004). Because those cattle were naturally infected, perhaps multiple strains were present, which could have contributed to difference among the methods in the number of positive samples (Medeiros et al., 2011). At the same time four different decontamination methods tested $\{0.75 \%$ $\mathrm{HPC}, 0.25 \% \mathrm{BC}, 5 \% \mathrm{OA}$ and $\left.6 \% \mathrm{H}_{2} \mathrm{SO}_{4}\right\}$ for bovine lymph nodes artificially contaminated with AN5 strain. They found that the $6 \%$ sulphuric and $0.75 \%$ HPC methods yielded the best result, due to lower toxicity present. These authors obtained similar results for HPC and $\mathrm{H}_{2} \mathrm{SO}_{4}$, which differ from our results. It is important to stress that the conservation procedure used by Holanda et al. (2002) for the lymph node samples, which were artificially contaminated with $M$. bovis, while in the present study the positive samples wereobtained from naturally infected animals. On the other hand, it is clear from table (4) and figure (1) that the lower contamination rate was found in using $\mathrm{HPC}(7.1 \%)$ followed by $\mathrm{H}_{2} \mathrm{SO}_{4}$ 
$(9.5 \%)$ and Oxalic (11. 9\%). The results in this study were in agreement with that reported by Kent and Kubica (1985) observed that the oxalic acid was useful in decontamination of specimens that are contaminated with pseudomonas. Moreover, Ambrosio et al. (2008) who showed that the contamination proportion of HPC was smallest (3\%), with significant difference compared to control group (88\%), $\mathrm{NaOH}(33 \%)$ and $\mathrm{H}_{2} \mathrm{SO}_{4}(21.7 \%)$. Bacteriological identification as shown in table (5) revealed that $27(81.8 \%)$ out of 33 cattle showing visible lesions were identified as $M$. bovis. The recovery rate of $M$. bovis is near to the results that obtained by Tammemagi et al. (1973) (89.1\%); Naglaa (2008) (70.59\%) and Rabab (2008) $(80 \%)$. Other investigators reported lower M. bovis recovery rate, Akeulah (1981) (32.7\%); Gallo et al. (1983) (5.5\%). While, $4(44.4 \%)$ out of 9 cattle without visible lesions were identified as M. bovis. This can be attributed to the fact that infection in those animals was in early stages or only microscopic lesions are found in lymph nodes of reactors and thus $M$. bovis could be recovered only on culture (Zeidan, 1971).

From results obtained in this study it could be recommended for sample processing of mycobacterium lesions to use the $0.75 \%$ HPC method for decontamination as it is the best than the other two methods $(5 \%$ oxalic acid and $6 \%$ sulphuric acid). Acknowledgment: This work was supported by Bovine Tuberculosis Project of Academics in Egypt with Department of Bacterial Diagnostic Products, Veterinary Serum and Vaccine Research Institute, Abassia, Cairo, Egypt.

\section{REFERENCES}

Akeulah, M.A. 1981. Investigation of atypical mycobacteria of some domestic animals. Ph. D. Thesis, Bacteriology, Immunology, Mycology, Fac. Vet. Med., Alexandria University.
Ambrosio, S.R., Oliveira, E.M., Rodriguez, C.A.R., Neto J.S.F., Amaku, M. 2008. Comparison of three decontamination methods for Mycobacterium bovis isolation. Brazilian Journal of Microbiology.39: 241- 244.

Ameni, G., Erkihun, A. 2007. Bovine tuberculosis on small - scale dairy farms in Adam Town, Central Ethiopia, and farmer awareness of the disease. Rev. Sci. Tech. Off. Int. Epiz., 26(3): 711- 719.

Borna, M., Penelope, V., Bongo, N., Colette, D., Irene S., Beatric M., Bruno O., Esther, S., Jakob, Z. 2009. Bayesian Receiver Operating Characterization Estimation of Multiple tests in Diagnosis of Bovine Tuberculosis in Chadian Cattle. PLOS ONE, 4: 1371-1381. Burdz, T.N., Wolfe, J., Kabani, A. 2003. Evaluation of sputum decontamination methods for Mycobacterium tuberculosis using viable colony counts and flow cytometry. Diag. Microbiol. Infect. Dis., 47: 503 - 509.

Chatterjee, M., Bahattcharya, S., Karak, K., Dastidar, S.G. 2013. Effect of different methods of decontamination for successful cultivation of Mycobacterium tuberculosis. Indian J.Med.Res.138: 541-548.

Cleaveland, S., Shaw, D.J., Mfinanga, S.G., Shirima, G., Kazwla, R.R., Eblate, E., Sharp M.2007.Mycobacterium bovis in rural Tanzania: risk factors for infection in human and cattle populations Tuberculosis.87(1): 3034.

Corner, L.A., Trajstman, A.C., Lund, K., 1995.Determination of the optimum concentration of decontaminants for primary isolation of Mycobacterium bovis. NZ Vet. J.,43:129- 133. Corner, L.A., Gormley, E., Pfeiffer, D.U. 2011.Primary isolation of Mycobacterium bovis form tissues: Condition for maximizing the number 
of positive cultures. Veterinary Microbiology. P: 1-10.

de la Rua- Domenech, R.A.T., Goodchild, H.M., Hewinson, R.G., Christiansen, K.H., Clifton - Hadley, R.S.2006. Ante mortem diagnosis of tuberculosis in cattle: A review of tuberculin tests, interferon assay and other ancillary diagnostic techniques. Res. Vet. Sci. 81:190-210. de Kantor, I.N., Lazlo, A. 1998.Tuberculosis laboratory procedure for developing countries in: Ganga dharan PRJ, editor Mycobacteria basic aspects, Vol. .1. New York: Chapman Hall II TP, 351 $-399$.

Elbattawy, E.H. 2008.Bacteriological characterization, molecular and immunological diagnostic assays for Mycobacterium infection in some animals. Thesis Ph.D. Minufiya University, Sadat City Branch Faculty of Veterinary Medicine, Department of Bacteriology Immunology and Mycology.

Gallo, J.A.G, Veitia, F., Remon, S., Delgado, L. 1983. Mycobacteria isolated from cattle reacted to tuberculin tests. Revista- Cubana Deciencias Vet., 14: 173-176.

Gonzales - Llamazares, O.R., Gutierrez Martain, C.B., Alvares - Nistal, D., Puente -Redondo, V., Domingue Rodriguez, L., Rodrigues - Ferri, E.F., De- La-Puente R.V.A. 1999. Field evaluation of the single intradermal cervical tuberculin test and the interferon - gamma assay for detection and eradication of bovine tuberculosis in Spain. Vet. Microbiology. 70(1): 55-66.

Holanda, ED., Lobato, F.C.F., Mota, P.M.P.C., Abreu, V.L.V. 2002. Avalacao de descontamincao para isolametode Mycobacterium bovis. Rev.Med. Vet., 24(2): 54-57. Kent, P.T., Kubica, GP. 1985. Public health mycobacteriology: a guide for the level III laboratory. U.S. Department of Health and Human Services, Centers for Disease Control and Prevention, Atlanta, GA

Laidlaw, M. 1989. Mycobacterium tubercle bacilli in: Collee, J.G., Duguid, J.P., Fraser, A.G., Marmion, B.P., editors, Mackie \&McCaroltney practical medical microbiology, Vol.2, Edinburgh: Churchill Living stone, 399-416.

Lotfy, O., Khater, A.R., Guindis, S.M. 1960.An investigation on tuberculosis Umakenan Village, Egypt, U.A.R.J. Egypt, Vet. Med. Ass., 20: 105- 112.

Marwa, M. 2011. Development and evaluation of new mycobacterial diagnostic reagents for detection of tuberculosis in cattle. Ph. D. Thesis, Bacteriology, Immunology, Mycology, Fac. Vet. Med., Cairo University.

Medeiros, L., Marassi, C.D., Duarte, R.S., de Silva, M.C., Lilenbaum, W.2011.Comparison of decontamination methods for primary isolation of Mycobacterium bovis in pancibacillary bovine tissues. Letters in Applied Microbiology. P: 1-5.

Murray, P.R., Baron, E.J., Jorgensen, J.H. 2007. Manual of clinical microbiology. American Society of Microbiology, Washington, DC.

Naglaa, R.A. Hassan 2008. Emergency Mycobacterium tuberculosis complex organisms: advances in diagnosis and drug resistance. Ph. D. Thesis, Bacteriology, Immunology, Mycology, Fac. Vet. Med., Cairo University.

Nasr, E.A. 1997. Studies on atypical mycobacterial microorganisms. Ph. D. Thesis, (Bacteriology, Immunology, Mycology), Fac. Vet. Med., Zagazig University.

OIE Terrestrial Manual 2009. Bovine tuberculosis, Chapter 2.4.7. Palmino, J.C., Portaelo, F.1998. Effects of decontamination methods and culture conditions on viability of Mycobacterium ulcerans in BACTEC 
system. Journal of Clinical Microbiology.36: 402- 408.

Rabab, M.I. El - Sawah 2008.Evaluation of different diagnostic tests used for diagnosis of bovine tuberculosis. M.V.SC. Thesis, Infectious Diseases, Fac. Vet. Med., Cairo University. Shirma, G.M., Kazwala, R.R., Kambarage, D.M. 2003. Prevalence of bovine tuberculosis in cattle in different farming systems in Eastern zone of Tanzania. Prev.Vet.Med., 57(3): 167- 172.

Streingart, K.R., Vivienne, N.G., Megan, A., Hopewell, P.C., Ramsay, A., Cunninghan J.2006. Sputum processing methods to improve the sensitivity of smear microscopy for tuberculosis. A systematic Review. Lancet Infect. Dis., 6: 664- 674.

Tammemagi, L., Simmons ,G.C., Kelman , R., Hall , W.T.K. 1973.A study of tuberculosis like lesions in cattle slaughtered in Queensland meat works. Aust. Vet. J., 49: 507- 511.

Thoen, CO., Lo Blue, P.A., Enarson, D.A., Kaneene, J.B., de Kantor, I.N. 2009. Tuberculosis: are emerging disease in animal and humans. Vetltal. 45: 135- 181.

Tomita, M., Takeno, H., Yoshida, S., Suzuiki, K., Sakatami, M. 2008. Comparison of BBL Mycoprep and 2
$\% \quad \mathrm{NaOH}$ decontamination procedures for MGIT. Kekkaku, 83: 471- 473.

Waddington, F.G. 1965. Observation on tuberculin sensitive in cattle in Kenya. Br.Vet.J., 121:319-331.

Wayne, L.G., Kubica, G.P. 1986.The mycobacteria. In Shean. P.H.A.; Sharpe, M.E.; Holt, J.G. (eds.) Bergey's Manual of Systematic Bacteriology. $8^{\text {th }}$ ed., Willianse WILKINS, Baltimore, V.e, Chap 6, P. 1435- 1457.

Yajko, D.M., Nassos, P.S., Sanders, C.A., Gonzalez, A.L.R., Horsbuburgh, C.R., Hopewell, P.C., Chainm, D.P, Hadley, W.K. 1993. Comparison of four decontamination methods for recovery of Mycobacterium avium complex from stools. Journal of Clinical Microbiology. Vol. 31(2): 302- 306.

Yesilkaya, H., Barer, M.R., Andrew, P.W. 2004. Antibiotic resistance may affect alkali decontamination of specimens containing mycobacteria. DiagenMicrobiol. Infect. Dis. 50: 153- 155.

Zeidan, M.A. 1971. Studies on T.B. in buffalo carcasses. M.V.SC. Thesis, Meat Hygiene, Fac. Vet. Med., Cairo University. 